\title{
Stabilization of Flail Chest and Fractured Sternum by Minimally Invasive Repair of Pectus Excavatum
}

\author{
Murat Akkuş ${ }^{1}$ Ayfer Utkusavaş ${ }^{2} \quad$ Murat Hanözü ${ }^{1}$ \\ 1 Department of Thoracic Surgery, Istanbul Mehmet Akif Ersoy \\ Thoracic and Cardiovascular Surgery Training and Research Hospital, \\ Istanbul, Turkey \\ 2 Department of Pulmonology, Istanbul Mehmet Akif Ersoy Thoracic and \\ Cardiovascular Surgery Training and Research Hospital, Istanbul, Turkey \\ ${ }^{3}$ Department of Cardiovascular Surgery, Istanbul Mehmet Akif Ersoy \\ Thoracic and Cardiovascular Surgery Training and Research Hospital, \\ Istanbul, Turkey
}

\author{
Mehmet Kaya ${ }^{3}$ Ihsan Bakir ${ }^{3}$
}

Thorac Cardiovasc Surg Rep 2015;4:11-13.

\begin{abstract}
Address for correspondence Mehmet Kaya, MD, Department of Cardiovascular Surgery, Istanbul Mehmet Akif Ersoy Thoracic and Cardiovascular Surgery Training and Research Hospital, Mehmet Akif Ersoy GKDC Eğitim Hastanesi Halkali Küçükçekmece, Istanbul 34000, Turkey (e-mail: drmehmetkaya@yahoo.com).
\end{abstract}
Abstract Keywords
- flail chest
- Nuss bar
- sternal fracture

We report a 55-year-old male patient with a massive flail chest that required chest stabilization by minimally invasive repair of pectus excavatum (MIRPE) employing a Nuss bar. Surgical stabilization of severe flail chest and fractured sternum with Nuss bar by MIRPE is a safe and useful treatment modality in properly selected patients.

\section{Introduction}

We would like to present the case of a patient with a massive flail chest sustained in a car accident. Multiple rib fractures and a sternal distal nondisplaced transverse fracture were observed bilaterally. This is a description of flail chest stabilization by minimally invasive repair of pectus excavatum (MIRPE) employing a Nuss bar.

\section{Case Description}

A 55-year-old male patient suffering from hypovolemic shock and flail chest resulting from a car accident was brought to the emergency clinic. Left-side tube thoracostomy had been performed by another medical center, with drainage of 2,000 mL hemorrhagic fluid. The patient was immediately taken into surgery. Through left lateral thoracotomy, total rupture of the pericardium and a $5 \times 6 \mathrm{~mm}$ left atrial appendix rupture were observed. After suture of the left atrial appendix and the pericardial wall, thoracotomy was formally closed and the intubated patient was taken to the intensive care unit (ICU). Postoperative vital parameters were stabilized. The flail chest resulted in dyspnea, which was treated by positive end-expiratory pressure on ventila- tor. As the patient could not be weaned from the ventilator 1 day after the operation, chest stabilization was deemed appropriate. On the 4th day, we decided on reconstruction of the flail chest by MIRPE. A three-dimensional computed tomography scan was taken to locate the fractured ribs and the sternum fracture (-Fig. 1). A Nuss bar was designed before surgery (-Fig. 2). The reconstruction operation was performed on the 5th day. With the help of a video-assisted thoracoscopic surgery, an introducer was inserted through the fifth intercostal space into the thorax. The sternum was elevated with towel clamps and stabilized temporarily with the introducer, while the fractured endpoints were aligned with the help of the thoracoscope. In effect, a single incision was made for the entry point, and both entry and exit were made through the corresponding sides of the fifth intercostal space. With the ends of the Nuss bar emanating from both sides of the chest, we elevated and aligned the fractured part of the sternum to reach the desired position. After Nuss bar insertion, precise inspection was performed by palpation through the skin to check for the existence of perturbed sternal bones. Immobility was provided by stabilizers (Pectus Excavatum System Bar, Medxpert GmbH, Heitersheim, Germany). Following chest stabilization, incisions were closed and the patient was taken to the ICU. The patient received

April 30, 2015

accepted after revision

June 26, 2015

published online

August 20, 2015
DOI http://dx.doi.org/

10.1055/s-0035-1563399. ISSN 2194-7635. (c) 2015 Georg Thieme Verlag KG
Stuttgart · New York

License terms

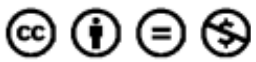




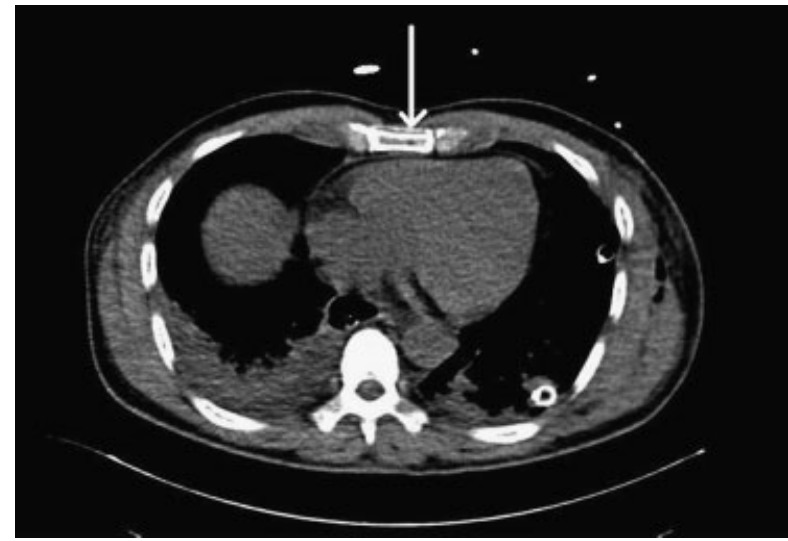

Fig. 1 Preoperative computed tomography scan focusing on the fractured sternum.

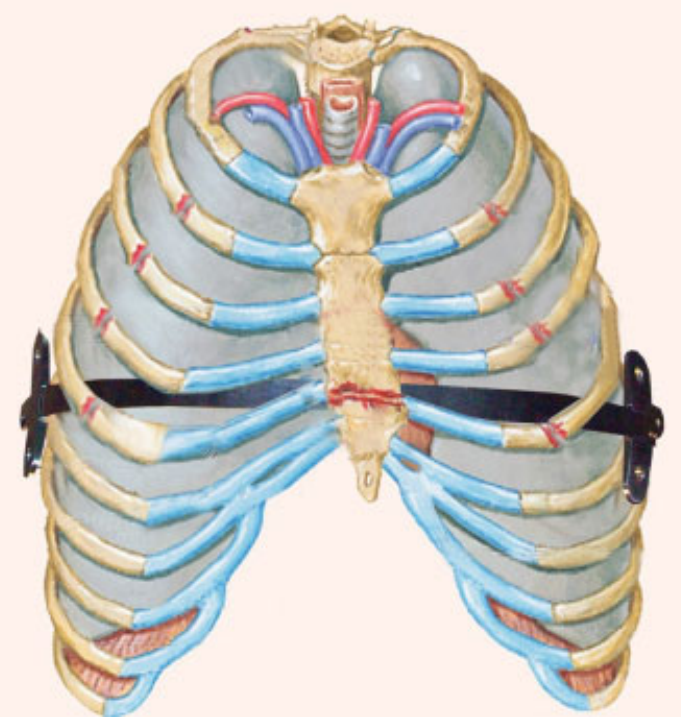

Fig. 2 Illustration of the flail chest and fractured sternum. was extubated 6 hours after the operation and was discharged from the hospital on the 14th postoperative day without any complications. No additional complications were observed during the follow-up period of 24 months (-Fig. 3).

\section{Discussion}

It is widely believed that respiratory impairment in patients with flail chest is only because of inefficient ventilation related to paradoxical movement of the chest wall, but evidence exists that it is also significantly influenced by other associated thoracic injuries, in particular pulmonary contusion and atelectasis. ${ }^{1}$ The use of positive pressure ventilation (internal support) results in improved patient outcomes related to early nonoperative and operative fixation. However, this technique requires prolonged time on the ventilator, resulting in secondary pulmonary infections and persistently high mortality rates of 10 to $36 \%$ in some series. ${ }^{2}$ In addition, positive pressure ventilation is not always able to reduce and stabilize bone injuries, resulting in painful fracture nonunion or symptomatic chest wall deformity in $64 \%$ of the cases in one study. ${ }^{3}$

External support techniques generally consist of suspension of the sternum or open reduction and internal fixation. Pacheco et $\mathrm{al}^{4}$ described the use of a Nuss bar in surgery for lateral flail chest performed through thoracotomy. ${ }^{4}$ In contrast, we used a Nuss bar by MIRPE, without thoracotomy, for stabilization of anterior flail chest and sternum after steering wheel injury.

Unlike Ke et $\mathrm{al}^{5}$ and Lee et $\mathrm{al}^{6}{ }^{6}$ our aim was to not only stabilize the chest, but also give considerable care and attention to the precise relocation and stabilization of the sternum. This was accomplished by the exact placement of the Nuss bar at the point of fracture. This further enabled reduced recovery time, which was essential in the specific case described as the patient had been extubated.

Another issue, a Nuss bar may apply a very strong force on the sternum and separate the segments. However, the purpose of the Nuss bar was to prevent backward movement of the sternum. In addition to this, we planned to keep the Nuss bar in place for 24 months, similar to pectus excavatum repair surgery.

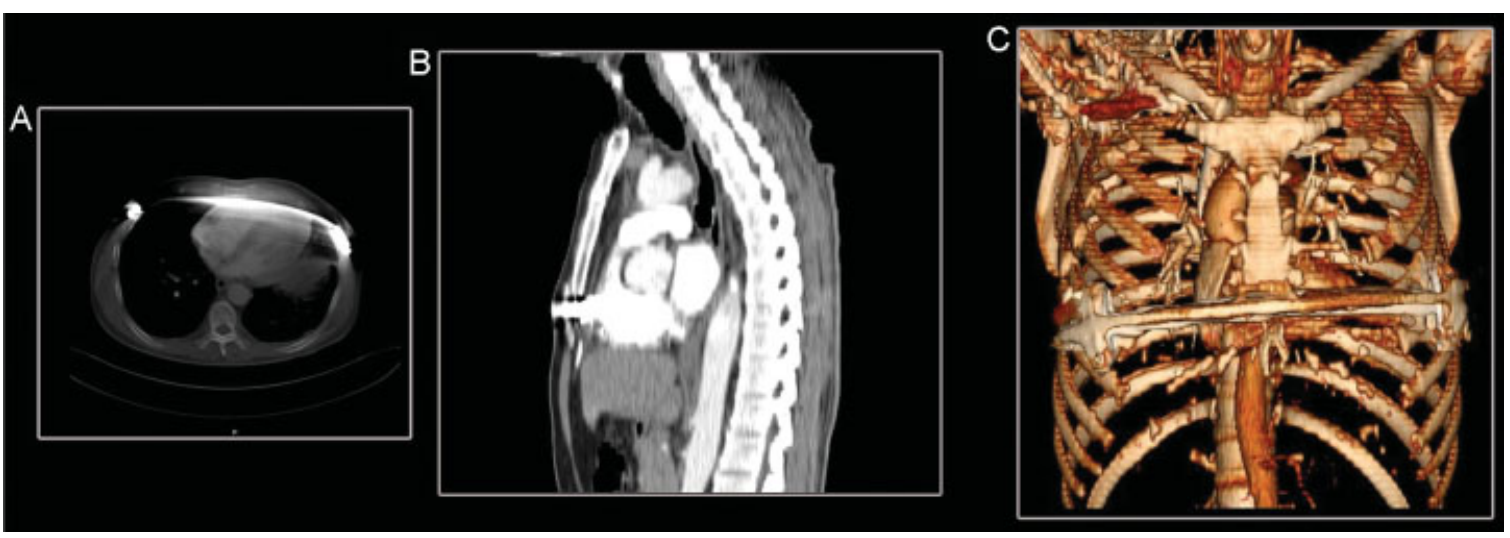

Fig. 3 After reconstruction, the appearance of the Nuss bar in axial (A), sagittal reformatted (B), and three-dimensional volumetric rendering (C) images by chest computed tomography. 
We conclude that surgical stabilization of severe flail chest and fractured sternum with Nuss bar by MIRPE is a safe and effective therapy in properly selected patients.

\section{References}

1 Gabram SG, Schwartz RJ, Jacobs LM, et al. Clinical management of blunt trauma patients with unilateral rib fractures: a randomized trial. World J Surg 1995;19(3):388-393

2 Cacchione RN, Richardson JD, Seligson D. Painful nonunion of multiple rib fractures managed by operative stabilization. J Trauma 2000;48(2):319-321
3 Fitzpatrick DC, Denard PJ, Phelan D, Long WB, Madey SM, Bottlang M. Operative stabilization of flail chest injuries: review of literature and fixation options. Eur J Trauma Emerg Surg 2010;36(5):427-433

4 Pacheco PE, Orem AR, Vegunta RK, Anderson RC, Pearl RH. The novel use of Nuss bars for reconstruction of a massive flail chest. J Thorac Cardiovasc Surg 2009;138(5):1239-1240

5 Ke S, Duan H, Cai Y, Kang J, Feng Z. Thoracoscopy-assisted minimally invasive surgical stabilization of the anterolateral flail chest using Nuss bars. Ann Thorac Surg 2014;97(6): 2179-2182

6 Lee SA, Hwang JJ, Chee HK, Kim YH, Lee WS. Flail chest stabilization with Nuss operation in presence of multiple myeloma.J Thorac Dis 2014;6(5):E43-E47 